$\begin{array}{cc}\text { http://www.jrdms.dentaiau.ac.ir } & \begin{array}{c}\mathrm{e}(\mathrm{ISSN}): 2383-2754 \\ \mathrm{p}(\mathrm{ISSN}): 2588-4166\end{array} \\ \text { JRDMS Journal of Research in Dental and Maxillofacial Sciences }\end{array}$

\title{
Hyper-IgM Immunodeficiency with Enamel Defects: a Case Report
}

\author{
Rahmani $\mathbf{N}^{1}$,Salem K ${ }^{2}$, Moazemi $\mathbf{F}^{3}$ \\ ${ }^{\prime}$ Postgraduate Student Pediatric Dentistry Dept,Dental Branch of Tehran, Islamic Azad University, Tehran, Iran. \\ ${ }^{2}$ Assistant prof, Pediatric Dept, Dental Branch of Tehran, Islamic Azad University, Tehran, Iran. ${ }^{3}$ Dentist \\ ${ }^{3}$ Dentist
}

\begin{tabular}{l}
\hline ARTICLE INFO \\
\hline Article Type \\
Case Report \\
\hline Article History \\
Received: Sep 2017 \\
Accepted: Nov 2017 \\
ePublished: Jan 2018
\end{tabular}

Keywords:

Hyper-IgM

Immunodeficiency

Syndrome,

Immunoglobulins,

Enamel Hypoplasia

\begin{abstract}
Background and Aim: Hyper-Immunoglobulin M (IgM) syndrome (HIGM) is a rare primary immunodeficiency in which defective B-cell isotype switching results in a phenotype characterized by elevated or normal serum IgM levels and low levels of other Ig classes, leading to an increased susceptibility to infection, neutropenia, autoimmune disorders, and malignancies. In this disease, a mutation occurs in the CD40 gene, leading to combined B-cell and T-cell immunodeficiencies. The oral manifestations include wound-like lesions, oral candidiasis, gingivitis, periodontitis, and enamel defects. Theoretically, systemic conditions affecting ameloblastic activity during enamel mineralization, such as abnormal oxygen levels resulting from hypoventilation in various respiratory diseases, result in enamel defects.

Case presentation: We report a 10-year-old male with hyper-IgM immunodeficiency. The patient had suffered from frequent infections, respiratory problems, and bronchopneumonia from the age of 2 years. At 4 years of age, type 1 diabetes mellitus was diagnosed. During dental examinations, enamel defects were found in seven permanent teeth.

Conclusion: A meticulous dental evaluation of children with systemic diseases is mandatory in order to discover possible developmental dental defects and to plan early interventions.
\end{abstract}

Please cite this paper as: Rahmani N, Salem K, Moazemi F. Hyper-IgM ImMunodeficiency with Enamel Defects: A case report. J Res Dent maxillofac Sci. 2018; 3 (1):34-38. 


\section{Introduction:}

Hyper-Immunoglobulin M (IgM) syndrome (HIGM) is a rare genetic primary immunodeficiency disorder with reduced levels of IgA, $\mathrm{IgG}$, and $\operatorname{IgE}$ and normal or increased levels of $\operatorname{IgM} .^{(1-3)}$

The inheritance is usually X-linked (XHIGM), but autosomal recessive and autosomal dominant forms have also been documented. ${ }^{(4-6)}$ XHIGM is caused by the defective expression of the CD40 ligand. A mutation in the CD40 gene leads to simultaneous immunodeficiency in B- and Tlymphocytes. Since the CD40 gene is necessary for the appropriate functioning of T-lymphocytes and macrophages, various defects are observed in this group of cells in a HIGM patient. ${ }^{(4,5)}$ Most HIGM patients show clinical signs during the first or second years of life, the most common of which are frequent infections, neutropenia, autoimmune diseases, and malignancies. ${ }^{(3,7-9)}$ Oral manifestations including wound-like lesions, oral candidiasis, gingivitis, periodontitis, and enamel defects have also been reported. ${ }^{(10,11)}$

Interferences during the enamel matrix secretion or enamel mineralization phases lead to hypoplasia or hypomineralization during amelogenesis. ${ }^{(12,13)}$

Based on the developmental defects of dental enamel (DDE index), enamel defects are categorized into three types including demarcated opacities, diffuse opacities, and hypoplasia. In a demarcated opacity defect, alteration in the translucency of enamel is obvious with a distinct border. This defect can be white, creamy, yellow, or brown. A demarcated opacity results from a trauma to ameloblasts during the maturation stage or from infections during the matrix secretion or early maturation stages. A diffuse opacity appears in the shape of a white line or patch with changes in the enamel translucency; however, there is no distinct boundary with the adjacent normal enamel. This defect has been associated with an arrest in enamel maturation. In enamel hypoplasia, the quantity and thickness of enamel have decreased. The affected tooth can be white, yellow, or brown with a rough or pitted surface. This is due to a damage during the enamel matrix secretion phase of amelogenesis.

Etiologic factors related to DDE are divided into two categories: the factors with a localized distribution including trauma, localized infection, and irradiation, and those with a generalized distribution including genetic and environment. Infectious diseases and other medical conditions are possible environmental etiologic factors for DDE. ${ }^{(13-15)}$

Here, we report a 10-year-old male with hyper-IgM immunodeficiency. Demarcated enamel opacities were detected in seven permanent teeth.

\section{Case presentation:}

The following is a case report of a 10 -year-old male who referred to the department of pediatric dentistry of the dental branch of Islamic Azad University of Tehran for dental examination and treatment. There was no history of the disease in the siblings or other close relatives. Genetic evaluations had not been performed; however, as the siblings or other close relatives were not involved, the mutation may be the probable mode of inheritance.

In the medical history of the patient, it was reported that frequent infections, respiratory problems, and bronchopneumonia had occurred from the age of 2 years. As a result, immunological assessments were done for the patient, which showed a normal complete blood count (CBC) and serum Ig levels of $\operatorname{IgA}<5 \mathrm{mg} / \mathrm{dl}$ (N: 78-312), $\mathrm{IgG}<28.3 \mathrm{mg} / \mathrm{dl}(\mathrm{N}: 650-1500)$, IgM $275 \mathrm{mg} / \mathrm{dl}$ (N: 55-300), and $\mathrm{IgE}<10 \mathrm{IU} / \mathrm{ml}(\mathrm{N}<114)$, which led to the diagnosis of hyper-IgM immunodeficiency.

Afterwards, the patient received Intravenous Ig (IVIG) monthly with serum IgG trough levels of 500 to $800 \mathrm{mg} / \mathrm{dl}$. The responsible physician prescribed oral Trimethoprim/sulfamethoxazole (TMP/SMX, $1500 \mathrm{mg}$ divided into three equal doses, $\mathrm{q} 8 \mathrm{~h})$. At the age of 4 years, this antibiotic was replaced with oral Azithromycin $(10 \mathrm{mg} / \mathrm{kg}$ as a single dose on the first day).

At 4 years of age, after vomiting, diarrhea, severe malaise, and frequent urination, the patient referred to the children's medical center for 
blood glucose evaluation. The blood glucose level was reported to be $800 \mathrm{mg} / \mathrm{dl}$, which led to the diagnosis of type 1 diabetes mellitus. The family history was unclear with regard to diabetes.

During dental examinations, white/creamy opacities with well-defined borders were detected in seven permanent teeth including left maxillary premolars and first molar, left mandibular first molar, and right mandibular premolars and first molar (Figure $1 \mathrm{a}-\mathrm{c}$ ). Accordingly, a preventive approach was adopted which included fissure sealant, preventive resin restoration, fluoride therapy, and recall visits.
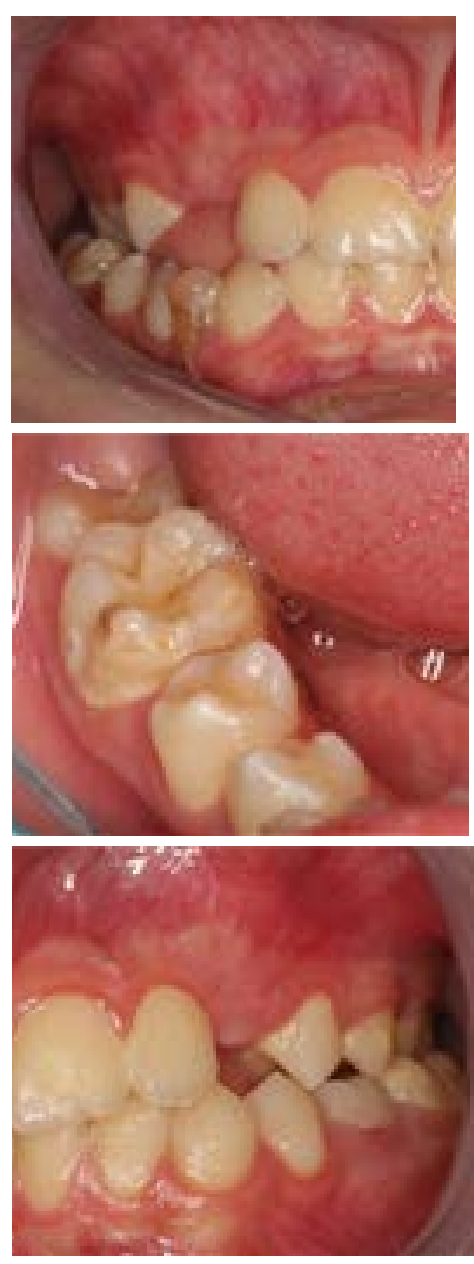

Figure 1. Intraoral photographs of white/ creamy opacities with well-defined borders in $(a, b)$ right mandibular premolars and first molar, and (c) left maxillary premolars and first molar and left mandibular first molar

\section{Discussion:}

In 1974, the World Health Organization (WHO) called immunodeficiency with increased IgM levels as the Hyper-IgM syndrome or Hyper-IgM immunodeficiency (HIGM). In 2015, the International Union of Immunological Societies (IUIS) called XHIGM the CD40 ligand deficiency in the classification of primary immunodeficiencies. ${ }^{(16)}$

The CD40 ligand is a transmembrane protein (TP) that is expressed on the surface of activated T-lymphocytes, and as a growth and differentiation factor, it could influence both Tand B-lymphocytes. ${ }^{(17,18)}$

HIGM patients experience recurrent infections, especially in the respiratory and gastrointestinal (GI) tracts. Neutropenia, thrombocytopenia, and anemia are common symptoms of blood cell involvement. ${ }^{(19)} \mathrm{Up}$ to two-thirds of patients with XHIGM syndrome suffer from episodic, cyclic, or chronic neutropenia. The physiological basis of the neutropenia is unknown; however, the affected patients respond well to treatment with the granulocyte-colony stimulating factor (G-CSF). ${ }^{(20)}$

There is also an increased incidence of autoimmune diseases such as diabetes mellitus, chronic arthritis, hypothyroidism, and kidney disease. ${ }^{(21,22)}$

GI involvement is common in HIGM patients, and diarrhea and malabsorption are the most severe symptoms. Finally, malignancies are seen as liver and GI tract cancers which can be life-threatening in these patients. ${ }^{(23-25)}$ The main line of treatment is Ig replacement in the form of IVIG that increases the level of IgG antibodies while decreasing the level of IgM antibodies. Patients with primary immunodeficiency diseases should not receive vaccines containing live viruses. ${ }^{(26)}$

Patients with HIGM show a significantly high frequency of oral and dental manifestations including herpes sores, candidiasis, tonsillitis, gingivitis, calculi, and enamel hypoplasia. ${ }^{(27)}$

Enamel is produced by ameloblasts during a certain period of dental development that is sensitive to environmental changes during amelogenesis.

Amelogenesis occurs in three consecutive 
phases. The first phase includes secretion of enamel matrix that occurs after the formation of the first layer of dentin and continues until a complete thickness of enamel is formed. The second and third phases, respectively, include enamel calcification and maturation. ${ }^{(12-14)}$ Damages during the enamel matrix secretion phase lead to the formation of a thin enamel, and if the damage occurs during the second and third stages, a chalky opaque porous enamel will be observed. ${ }^{(28)}$

In the present case, enamel defects were observed in seven permanent teeth including left maxillary premolars and first molar, left mandibular first molar, and right mandibular premolars and first molar. These defects were white/creamy opacities with well-defined borders. Based on the DDE index, these defects were considered as demarcated opacities. Weerheijm et al used the term "molar incisor hypomineralization" (MIH) to describe a more specific DDE pattern, i.e. "hypomineralization of systemic origin of one to four permanent first molars frequently associated with affected incisors". The second permanent molars and premolars are rarely affected by these enamel defects. Hypomineralization presents as an anomaly in the tissue translucency, creating a white or yellow/brownish area that may be asymmetrical. ${ }^{(29-31)}$

The crown formation of permanent teeth, except for the third molar, begins at birth and completes at around the age of 8 years. A damage to ameloblasts during this period may cause DDE. Regarding the first permanent molar, the beginning of the formation of hard tissue is at birth, while the completion of enamel formation takes up to 2.5-3 years. The enamel formation process in maxillary and mandibular first premolars begins around 1.5 years of age and completes at the age of 5-6 years. This timing in secondary premolars is around 2 years of age and 6-7 years of age, respectively. ${ }^{(32,33)}$ Furthermore, the occurrence of respiratory infections at the age of 2 years in the present case can justify the occurrence of DDE, which is probably MIH in first permanent molars and premolars, coinciding with the chronological age.

Our findings suggest that HIGM patients are probably at greater risks for DDE; this is in agreement with the result of a previous study by Meighani et al with regard to a more extensive enamel hypoplasia in patients with primary antibody deficiencies compared to the controls. (27) However, due to the scarcity of HIGM, a definitive conclusion cannot be made with regard to these patients. DDE may cause increased tooth sensitivity and an increased risk of dental caries. (34) On the other hand, teeth with DDE are 10 times more in need of treatment than normal teeth. ${ }^{(35)}$

Most of the information about the etiology of DDE has been obtained from case reports of children with systemic diseases; this emphasizes the importance of the case reports related to DDE in systemic disorders.

\section{Conclusions:}

A meticulous dental evaluation of children with systemic disorders is advised in order to discover possible developmental dental defects and to plan early interventions. Furthermore, it is essential for dentists to become familiar with the etiological factors of enamel defects.

\section{References:}

1.Silva R, Da Costa JT. Hyper-IgM Syndrome - a case report and a clinical perspective. Eur Ann Allergy Clin Immunol. 2010 Oct;42(5):194-6.

2.Revy P, Muto T, Levy Y, Geissmann F, Plebani A, Sanal O, et al. Activation-induced cytidine deaminase (AID) deficiency causes the autosomal recessive form of the Hyper-IgM syndrome (HIGM2). Cell. 2000 Sep $1 ; 102(5): 565-75$.

3.Winkelstein JA, Marino MC, Ochs H, Fuleihan R, Scholl PR, Geha R, Stiehm ER, Conley ME. The Xlinked hyper-IgM syndrome: clinical and immunologic features of 79 patients. Medicine (Baltimore). 2003;82(6):373-84.

4.Notarangelo LD, Hayward AR. X-linked immunodeficiency with hyper-IgM (XHIM). Clin Exp Immunol. 2000 Jun; 120(3):399-405.

5.Etzioni A, Ochs HD. The hyper IgM syndrome--an evolving story. Pediatr Res. 2004 Oct;56(4):519-25.

6.Bhushan A, Covey LR. CD40:CD40L interactions in X-linked and non-X-linked hyper-IgM syndromes. Immunol Res. 2001;24(3):311-24.

7.Thusberg J, Vihinen M. The structural basis of hyper IgM deficiency-CD40L mutations. Protein Eng Des Sel. 2007 Mar;20(3):133-41.

8.Stray-Pedersen A, Abrahamsen TG, Frøland SS. Primary immunodeficiency diseases in Norway. J Clin 
Immunol. 2000 Nov;20(6),477-85.

9.Chan HY, Yang YH, Yu HH, Chien YH, Chiang LL, Chiang BL. Clinical characteristics and outcomes of primary antibody deficiency: a 20-year follow-up study. J Formos Med Assoc. 2014 Jun; 113(6):340-8.

10. Aghamohammadi A, Moin M, Karimi A, Naraghi M, Zandieh F, Isaeian A, et al. Immunologic evaluation of patients with recurrent ear, nose, and throat infections. Am J Otolaryngol. 2008 Nov-Dec; 29(6):385-92.

11. Fernandes KS, Lima MB, Martins CP, Dos-Santos MC, Nunes FD, Kokron CM, et al. Salivary Immunoglobulins in Individuals with Common Variable Braz Dent J. 2016 Oct-Dec;27(6):641-5.

12. Mahoney EK, Ismail FSM, Kilpatrick N, Swain M. Mechanical properties across hypomineralized/hypoplastic enamel of first permanent molar teeth. Eur J Oral Sci 2004; 112: 497-502.

13. Wong HM. Aetiological Factors for Developmental Defects of Enamel. Austin J Anat. 2014; May;1(1):1003.

14. Negre-Barber A, Montiel-Company JM, CataláPizarro M, Almerich-Silla JM. Degree of severity of molar incisor hypomineralization and its relation to dental caries.

Sci Rep. 2018 Jan 19;8(1):1248.

15. Lo EC, Zheng CG, King NM. Relationship between the presence of demarcated opacities and hypoplasia in permanent teeth and caries in their primary predecessors. Caries Res. 2003 Nov-Dec;37(6):456-61.

16. Bousfiha A, Jeddane L, Al-Herz W, Ailal F, Casanova JL, Chatila T, et al. The 2015 IUIS Phenotypic Classification for Primary Immunodeficiencies. J Clin Immunol 2015 Nov;35(8):727-38.

17. Kawabe T, Matsushima M, Hashimoto N, Imaizumi K, Hasegawa Y. CD40/CD40 ligand interactions in immune responses and pulmonary immunity. Nagoya J Med Sci. 2011 Aug;73(3-4):69-78.

18. Elgueta R, Benson MJ, de Vries VC, Wasiuk A, Guo $\mathrm{Y}$, Noelle RJ. Molecular mechanism and function of CD40/CD40L engagement in the immune system. Immunol Rev. 2009 May;229(1):152-72.

19. Lee WI, Torgerson TR, Schumacher MJ, Yel L, Zhu Q, Ochs HD. Molecular analysis of a large cohort of patients with the hyper immunoglobulin $\mathrm{M}(\operatorname{IgM})$ syndrome. Blood. 2005 Mar 1;105(5):1881-90.

20. Macpherson AJ, Martinic MM, Harris N. The functions of mucosal $\mathrm{T}$ cells in containing the indigenous flora of the intestine. Cell Mol Life Sci. 2002 Dec;59(12):208896.

21. Jesus AA, Duarte AJ, Oliveira JB. Autoimmunity in hyper-IgM syndrome. J Clin Immunol. 2008 May;28 Suppl 1:S62-6.

22. Bussone G, Mouthon L. Autoimmune manifestations in primary immune deficiencies. Autoimmun Rev. 2009 Feb;8(4):332-6.

23. Eren M, Saltik-Temizel IN, Yüce A, Cağlar M, Koçak
N. Duodenal appearance of giardiasis in a child with selective immunoglobulin A deficiency. Pediatr Int. 2007 Jun;49(3):409-11.

24. Korponay-Szabó IR, Dahlbom I, Laurila K, Koskinen S, Woolley N, Partanen J, et al. Elevation of IgG antibodies against tissue transglutaminase as a diagnostic tool for coeliac disease in selective IgA deficiency. Gut. 2003 Nov;52(11):1567-71.

25. Kumar V, Jarzabek-Chorzelska M, Sulej J, Karnewska K, Farrell T, Jablonska S. Celiac disease and immunoglobulin A deficiency: how effective are the serological methods of diagnosis? Clin Diagn Lab Immunol. 2002 Nov;9(6):1295-300.

26. Medical Advisory Committee of the Immune Deficiency Foundation, Shearer WT, Fleisher TA, Buckley RH, Ballas Z, Ballow M, et al. Recommendations for live viral and bacterial vaccines in immunodeficient patients and their close contacts. J Allergy Clin Immunol. 2014 Apr;133(4):961-6.

27. Meighani G, Aghamohammadi A, Javanbakht H, Abolhassani H, Nikayin S, Jafari SM, et al. Oral and dental health status in patients with primary antibody deficiencies. Iran J Allergy Asthma Immunol. 2011 Dec;10(4):28993.

28. Kanchan T, Machado M, Rao A, Krishan K, Garg AK. Enamel hypoplasia and its role in identification of individuals: A review of literature. Indian J Dent. 2015 AprJun;6(2):99-102.

29. Sapir S, Shapira J. Clinical solutions for developmental defects of enamel and dentin in children. Pediatr Dent. 2007 Jul-Aug;29(4):330-6.

30. Allazzam SM, Alaki SM, El Meligy OA. Molar incisor hypomineralization, prevalence, and etiology. Int J Dent. 2014;2014:234508.

31. Garg N, Jain AK, Saha S, Singh J. Essentiality of early diagnosis of molar incisor hypomineralization in children and review of its clinical presentation, etiology and management. Int J Clin Pediatr Dent. 2012 Sep;5(3):190-6.

32. Weerheijm KL, Duggal M, Mejàre I, Papagiannoulis L, Koch G, Martens LC, et al. Judgement criteria for molar incisor hypomineralisation (MIH) in epidemiologic studies: a summary of the European meeting on MIH held in Athens, 2003. Eur J Paediatr Dent. 2003 Sep;4(3):110-3.

33. Ikeda Y, Neshatian M, Holcroft J, Ganss B. The enamel protein ODAM promotes mineralization in a collagen matrix. Connect Tissue Res. 2018 Dec;59(sup1):62-6.

34. Wong HM, McGrath C, King NM. Dental practitioners' views on the need to treat developmental defects of enamel. Community Dent Oral Epidemiol. 2007 Apr;35(2):130-9.

35. Jälevik B, Klingberg GA. Dental treatment, dental fear and behaviour management problems in children with severe enamel hypomineralization of their permanent first molars. Int J Paediatr Dent. 2002 Jan;12(1):24-32. 